\title{
Setting up a new regional child and family psychiatry unit: the involvement of referrers
}

\author{
Michelle Park, Research Psychologist; Arturo Langa, Registrar, Helen Likierman, \\ formerly Senior Clinical Psychologist; and CHRISTOPHER EVERED, Consultant Child \\ Psychiatrist, (correspondence), Collingham Gardens Child and Family Psychiatry \\ Unit, 5 Collingham Gardens, London SW5 0HR
}

The North West Thames Regional Health Authority rationalised its in-patient service in 1989 to fund an eight-bedded five day unit for children under 13 years of age at Collingham Gardens. Riverside Health Authority's District Child Psychiatric Day Unit was also relocated to provide ten places primarily for pre-adolescent children. The unit is staffed by a multidisciplinary team of child workers, nurses, occupational therapists, psychologists, psychiatrists, teachers, and a psychotherapist, social worker and speech therapist.

The involvement of families in decisions about admission is important. Other units have found that the most successful admissions have been those where the decision and motivation have come from the family (Hildebrand et al, 1981; LaBarbera et al, 1982, Bruggen \& O'Brien, 1987). Work on the unit focuses on achieving the changes agreed with the family prior to admission to enable the child to return to his/her family and community. Change is facilitated through family meetings and individually designed treatment programmes. It is important that discharge occurs only when sufficient positive change has occurred for the family to be able to maintain this development (Hildebrand et al, 1981).

In this paper we examine the importance of a new unit establishing an ongoing relationship with referrers, and the value of involving referrers in admission decisions.

The unit operates as a tertiary service, providing resources additional to those available locally. The majority of referrals are from specialist child mental health services. The work at the unit is more intensive but not independent from these services. It is important that referrers perceive the service to be linked to their work rather than one which operates in a vacuum. Indeed the referrers' own assessment and experience helps to focus the unit's intervention.

Involving referrers and unit staff in meetings, before and during admission, develops good liaison and facilitates continuity of treatment after discharge. The admission policy consists of four stages.

(a) After a referral has been received (by letter or telephone), a telephone discussion is held with the referrer to discuss the reasons for it, involvement of other professionals, to obtain details of the family and explore the use of an admission.

(b) A consultation with referrer, family and other involved professionals is offered at the referrer's place of work. The focus of this is to gain information about possible reasons for admission from all present, give the family information about the unit, and provide an intervention which may lead to other solutions to the problem or a decision by the family to visit the unit.

(c) During the assessment meeting at the unit, the family (or whoever has legal responsibility for the child) will decide whether to request an admission, the reasons for it, and the changes necessary for discharge.

(d) Children are initially admitted full time for a four to six week assessment period after which the length of admission is negotiated according to goals set. During admission referrers and professionals are invited to review and discharge meetings.

\section{Evaluation of unit}

Research carried out during the unit's first year of operation, February 1989 to January 1990, aimed to establish a framework for monitoring and evaluating the unit, defining clinical policy and planning service development and future research. Areas examined included an investigation of the unit referral policy and process, referral and admission statistics, and questionnaire feedback from referrers, professionals and families on service satisfaction and effectiveness (Park \& Likierman, 1990).

To learn the 41 referrers' responses to the new service questionnaires were distributed to:

Group $A$ referrers who chose to have a telephone discussion only as a consultation was not required;

Group B referrers who were given a consultation and a decision was made not to admit the child; 
Group $C$ referrers of children who were admitted to the unit.

Response rates were: Group A 78\%, Group B $85 \%$ and Group C $89 \%$.

\section{Findings}

Results (Table I) indicate that $86 \%$ of referrers found a telephone discussion or consultation extremely useful or useful. Many commented that this had helped them to clarify the need to focus on goals for change, provided valuable insight into the case, improved their decision making and in some cases confirmed their view of the case. Referrers also commented that the consultation facilitated communication with other institutions and agencies.

In one case where the child's presenting problems deteriorated during admission to the unit, the referrer felt that the consultation had still been useful and that the work of the unit clarified issues to enable placement away from home after discharge.

Results (Table II) indicate that the great majority of referrers in all three groups $(69 \%)$ were satisfied with the overall service provided by the unit.

The one referrer in Group A who was fairly dissatisfied required greater clarification of the unit's referral policy although this was during an early stage of the unit's development. Only one referrer was dissatisfied with the outcome of the consultation. In this case, admission did not occur as the parent was unable to gain control at home and the child was taken into care. Two referrers felt they had had insufficient contact with the unit to be able to comment on the service as a whole. Of the 41 referrers, $98 \%$ said they would refer again while only one referrer was "unsure".

\section{Comment}

The results indicate that the current referral process involving telephone discussion and consultation has proved valuable to referrers in the following ways. First, they are useful in clarifying the options available and in suggesting other agencies to contact. Second, they provide a new focus for out-patient work by promoting solutions from within the family and thereby avoid the need for an admission. Third, meetings facilitate the decision-making of families and professionals, for example, to seek long term placement in a therapeutic community. Fourth, the admission process functions as a filter to in-patient facilities (Wells, 1989). This ensures only the most appropriate referrals are admitted to the unit.

Although it is sometimes difficult for referrers when a decision is made not to admit a child, we have found that their active involvement increases understanding and satisfaction with the service. However future research should examine further families'
TABLE I

Usefulness of telephone discussion (Group A) and consultation (Groups B \& C)

\begin{tabular}{llll}
\hline & \multicolumn{3}{c}{ Referrer groups } \\
Referrer response & A & B & C \\
& $\mathrm{n}=7 / 9$ & $\mathrm{n}=11 / 13$ & $\mathrm{n}=17 / 19$ \\
\hline & & & \\
Extremely useful/ & $5(71 \%)$ & $6(55 \%)$ & $7(41 \%)$ \\
Useful & $2(29 \%)$ & $5(45 \%)$ & $5(29 \%)$ \\
Moderately useful & 0 & 0 & $3(18 \%)$ \\
Not particularly useful & 0 & 0 & 0 \\
Not at all useful & 0 & 0 & $2(12 \%)$ \\
Did not attend meeting & 0 & 0 & \\
\hline
\end{tabular}

TABLE II

Overall satisfaction with the service. Telephone discussion (Group A) and consultation (Groups B \& C)

\begin{tabular}{llll}
\hline & \multicolumn{3}{c}{ Referrer groups } \\
Referrer response & $\begin{array}{c}\text { A } \\
\text { B }\end{array}$ & C \\
& $\mathrm{n}=7 / 9$ & $\mathrm{n}=11 / 13$ & $\mathrm{n}=17 / 19$ \\
\hline $\begin{array}{l}\text { Very satisfied/ } \\
\text { Fairly satisfied }\end{array}$ & $4(57 \%)$ & $7(64 \%)$ & $10(76 \%)$ \\
$\begin{array}{l}\text { Neither satisfied nor } \\
\text { dissatisfied }\end{array}$ & $2(29 \%)$ & $1(9 \%)$ & $7(24 \%)$ \\
Fairly dissatisfied & $1(14 \%)$ & $1(9 \%)$ & 0 \\
Very dissatisfied & 0 & 0 & 0 \\
Other & 0 & $2(18 \%)$ & 0 \\
\hline
\end{tabular}

decisions not to take up treatment and find out what, if any, treatment facilities are used.

Denner \& Halprin stated in 1974 that psychiatric "services should be designed to meet the needs of the people served and that professionals should make themselves accountable to the people they serve". Questionnaire feedback provided an opportunity to develop the relationship between the unit and referrers by enabling referrers to suggest modifications to the future operation of the unit. In light of the recommendations of 1989 Working for Patients White Paper, and the importance currently being assigned to audit, it will continue to be important for the unit to maintain monitoring and evaluating its responsiveness to the needs of all its consumers: referrers, professionals and families.

\section{Acknowledgements}

We are grateful to the staff of Collingham Gardens Child and Family Psychiatry Unit for developing its policy and for commenting on the draft; to Dr P. Bruggen for his helpful comments, and to referrers for responding to the questionnaires. 


\section{References}

Bruggen, P. \& O'BrIEN, C. (1987) Helping Families Systems, residential and agency responsibility. London: Faber \& Faber.

DenNeR, B. \& Halprin, F. (1974) Measuring consumer satisfaction in a community outpost. American Journal of Community Psychology, 2, 13-22.

Hildebrand, J., Jenkins, J., Carter, D. \& Lask, B. (1981) The introduction of a full family orientation in a child psychiatric in-patient unit. Journal of Family Therapy, 3, 139-152.
LaBarbera, J., Martin, J., Dozier, E. (1982) Residential treatment of males: the influential role of parental attitudes. Journal of the American Academy of Child Psychiatry, 21, 286-290.

PARK, M. \& LikIERMan, H. (1990) Collingham Gardens Child and Family Psychiatry Unit First Year Evaluation Report. Riverside Health Authority.

Wels, P. (1989) Why admit to a bed? Disposal of 1,000 referrals to a Regional Adolescent Service. Psychiatric Bulletin, 13, 342-344.

\title{
Whither the disturbed patient: a study of regional secure unit referrals from two health districts
}

\author{
George J. Lodge, Consultant Psychiatrist, Roundway Hospital, Devizes, \\ Wiltshire SN10 5DS
}

Roundway Hospital provides all rehabilitation and continuing care (rehab) beds for the Swindon Health District (Swindon), population 245,000; the Wiltshire sector of the Bath Health District (Wilts) population 200,000; and the Bath City sector of the Bath Health District (Bath), population 85,000.

Like other similar hospitals it has seen enormous reductions in bed use. Recently, however, managerial pressure to reduce bed numbers to finance service developments has overtaken clinical initiative. These reductions have been accompanied by a dramatic increase in the two districts' use of the Wessex Regiona Secure Unit (RSU) to deal with violent disturbed patients from one admission in 1981 to ten during 1989.

Might this apparent increasing difficulty in coping with disturbed violent patients be linked with the shrinking and threatened closure of the asylum?

\section{The shrinking asylum}

A first look at the statistics showed that early in the decade, Swindon was the major referrer. This might be accounted for by higher intrinsic rates of disturbance (Swindon is a rapidly expanding town) or by insufficient acute bed provision. Swindon's provision in 1981 was 0.26 beds/ 1000 population c.f. $0.35 / 1000$ and $0.33 / 1000$ for Wilts and Bath respectively. By 1989 the acute bed provision for the three areas was nearer equity: $0.25,0.30$ and $0.25 / 1000$ respectively and the ratio of admissions to the RSU (4:4:2) much closer to population ratios. When, however, the correlation between RSU admissions and changes in acute bed provision was calculated for the years 1981-1989, this proved non-significant: $R=-0.16$.

New and old long-stay rehab beds have reduced from $0.69,0.7$ and 0.2 per 1000 for Swindon, Wilts and Bath in 1981 to $0.18,0.21$ and 0.15 per 1000 respectively in 1989 . There is a highly significant correlation between RSU admissions and reductions in these beds: $R=0.93 ; P<0.001$. The correlation is slightly weaker with percentage annual rehab bed reductions: $R=0.86 ; P<0.01$. Other figures (total institution size and combined acute and rehab bed reduction) also show significant correlations, though less strong.

\section{Underlying factors}

One reason for increased use of the RSU might be an impairment of the institution's capacity to admit because of too rapid a rate of change. If so, then one might expect that increasing numbers of referrals might come direct from DGHs, courts, prisons and the community. This proved to be the case, with a highly significant correlation between referrals from these sources and overall referrals: $R=0.94$; $P<0.001$

Were we referring less disturbed patients? If so, then length of stay at the RSU might be shorter. 